\title{
粚
}

\section{Die betekenis van charisma en amp vir die kerkregering}

\author{
A. le R. (Dries) du Plooy \\ Skool vir Kerkwetenskappe \\ Potchefstroomkampus \\ Noordwes-Universiteit \\ POTCHEFSTROOM \\ E-pos: dtlaldp@puk.ac.za
}

\begin{abstract}
The significance of charisma and office for church polity

This article focuses on Biblical concepts such as "charisma" and "office" and their importance and significance for the pure government of the church. We look at the concepts of "charisma" (gift) and "office" and proceed to describe the relationship between the two. From Scripture it becomes evident that there should be no tension between the charismata and the offices. In fact, the offices in the church are part of the charismata God has given to the church together with the gift of the Holy Spirit. It is argued that everyone who has been called to serve in an office needs to be blessed with the necessary gifts or charismata, so as to contribute to the equipment and building up of the church. Effective church polity depends on a true and solid understanding of these concepts.
\end{abstract}

\section{Opsomming}

Die betekenis van charisma en amp vir die kerkregering

In hierdie artikel word die fokus geplaas op Bybelse begrippe soos "charisma" en "amp" en daar word aangedui hoe belangrik en betekenisvol hierdie begrippe vir 'n suiwere kerkregering is. Agtereenvolgens word aandag gegee aan die begrippe "charisma" en "amp" waarna die verhouding daartussen beskryf word. Uit die Skrif is dit duidelik dat daar geen spanning is tussen die genadegawes en die ampte nie. Die ampte is deel van die genadegawes wat God aan die kerk gegee het, saam met die gawe van die Heilige Gees. Dit word beredeneer dat elkeen wat geroep is om in 'n amp te dien, begenadig moet wees met die nodige genadegawe om sodoende betrokke te 
wees by die toerusting en opbou van die kerk. Effektiewe kerkregering is afhanklik van ' $n$ ware en suiwer begrip van hierdie konsepte.

\section{Inleiding}

\subsection{Cassie Venter as teologiese kollega}

Dit is 'n voorreg om met hierdie artikel 'n bydrae te lewer in 'n publikasie wat ter ere van en uit erkentlikheid teenoor prof. C.J.H. Venter aangebied word. Vir my is hy behalwe 'n jarelange en gewaardeerde vriend, ook 'n inspirerende kollega met wie ek en ander kollegas hartlik saamgewerk het.

Prof. Cassie Venter het as teoloog hom doelbewus as NuweTestamentikus en as diakonioloog (praktiese teoloog) bekwaam. Wanneer hy as praktiese teoloog gepubliseer het, het dit duidelik geword dat daar konsekwent 'n sterk Bybelse, veral NuweTestamentiese begronding in sy werk is; ook omgekeerd: wanneer hy as Nuwe-Testamentikus of biblioloog gedoseer of gepubliseer het, het dit altyd sterk toepassing gevind in die praktiese betekenis en implikasies daarvan.

Aangesien hy as diakonioloog onder meer gefokus het op die NuweTestamentiese begronding en funksionering van die ampte of dienste in die kerk van Jesus Christus, het ek geoordeel dat 'n onderwerp soos hierdie nie net by sy belangstelling aansluit nie, maar ook sal aandui hoe naby die vakgebiede van Praktiese Teologie en Kerkreg aan mekaar lê.

In een van sy artikels met die titel wat tipies aan hom is, Amp en ampsdraer - gesigspunte uit die Nuwe Testament (Venter, 1988:95107), het hy perspektiewe oor die ampte en veral ook oor die pneumatiese en charismatiese basis vir die ampte na vore gebring. Ek sluit graag in hierdie artikel daarby aan.

\subsection{Aktualiteit van die onderwerp}

Daar gaan stemme daarvoor op dat die tyd van die Gereformeerde Kerke en 'n gereformeerde wyse van kerkregering en kerklike inrigting verby is en dat die meer charismatiese en spiritualistiese wyse van kerkinrigting besig is om in die plek daarvan te tree (Burger, 2004:10).

Sommige mense praat van 'n "Tweede Reformasie" (Smith, 1999: 151 e.v.), en meen dat die eerste Reformasie van die sestiende eeu 
wel daarin geslaag het om die Bybel aan die kerk terug te gee, maar dat dit in gebreke gebly het om die bediening aan die gewone lidmate van die kerk te gee. Die sogenaamde Tweede Reformasie is in reaksie teen die kerkordelike en amptelike wyse van kerkregering.

Hierdie strominge en neigings is nie nuut of vreemd nie, maar tog veroorsaak dit ook in gereformeerde kringe twyfel en lei dit tot vrae oor die wyse van kerklike inrigting en kerkregering volgens die gereformeerde tradisie.

In hierdie artikel fokus ek op die betekenis wat die charisma en die amp het vir die regering van die kerk in die lig van die NuweTestamentiese getuienis.

Ek wil graag die onderwerp op die volgende wyse behandel:

- Die teenstrydigheid oor charisma en amp, soos dit gedurende die twintigste eeu van tyd tot tyd opgevlam het.

- Perspektief op die begrip charisma.

- Perspektief op die begrip amp.

- Verhouding tussen charisma en amp.

- Betekenis vir die kerkregering.

\section{Teenstrydigheid tussen charisma en amp}

Die vraag wat beantwoord moet word, is of daar 'n antitese bestaan tussen charisma en amp, of hoe sodanige verhouding beskryf of verstaan moet word.

Daar is inderdaad 'n gedagterigting wat 'n teenstelling vind tussen charisma en amp. Daarteenoor is ook die standpunt dat daar 'n besonder noue verband tussen die twee begrippe is.

\subsection{Antitetiese standpunte}

Binne die gedagterigting dat daar 'n antitese bestaan, kan die spiritualistiese en aktualistiese standpunte onderskei word. Aangesien dit redelik volledig bespreek is in publikasies (vgl Ridderbos, 1966:479 e.v.; Aucamp, 1981:19-21; Du Rand, 1988:8182; Fung, 1980:195-214), vestig ek hieronder die aandag slegs op die essensie in die onderskeie standpunte. 


\subsubsection{Spiritualistiese opvatting}

Die aanleidende gedagte waarvolgens die legitimiteit van die institusionele aard van die kerk bevraagteken is, is in die opvatting van Sohm (1892) en Harnack (1910). Enige kerkregtelike ordening was vir Sohm in stryd met die wese van die kerk en 'n Fremdkorper van die oorspronklike kerk (Ridderbos, 1966:439). Die kerk ontvang, volgens Sohm, sy leiding direk van die Gees, en moet deur die charismata in stand gehou word.

Harnack glo ook dat die kerk 'n sosiologiese en charismatiese gemeenskap is waar 'n charismatiese struktuur en administratiewe ordening belangrik is, maar dit bly egter ondergeskik aan die geestelike en charismatiese aard van die kerk (Du Rand, 1988:81).

Holl (1928) onderskei tussen die Joodse kerk, wat institusioneel van aard sou wees en die Pauliniese kerk wat charismaties sou wees.

\subsubsection{Aktualistiese opvatting}

Verteenwoordigers van hierdie standpunt is veral Kasemann, Schweizer en Von Campenhausen, hoewel hulle natuurlik verskillende nuanses voorstaan.

Volgens die aktualisitiese siening in die algemeen, is daar 'n totale konflik tussen die geestesgawes en enige vorm van organisasie onder leiding van die ampte in die kerk (Fung, 1980:195).

Veral Kasemann is daarvan oortuig dat daar nie uit Paulus se briewe afgelei kan word dat daar bepaalde ampte in die gemeentes gefunksioneer het nie. Hy meen dat alle gedooptes vanselfsprekend ampsdraers is en daarom het elkeen op charismatiese manier ' $n$ eiesoortige verantwoordelikheid. Sodoende verplaas die charismata die moontlikheid van die besondere ampsdraers, soos ouderlinge en diakens (Fung, 1980:204). Von Campenhausen sien die ampte as 'n ontwikkeling na die aanvanklike charismatiese fase (Du Rand, 1988:82).

\subsection{Die noue verband tussen charisma en amp}

Die sterk antitetiese standpunte is in die verloop van die 20ste eeu getemper deur die bydrae van mense soos Lauterburg, Michel en later veral deur Ridderbos, Goppelt en Gnilka (Lekkerkerker, 1971:97; Du Rand, 1988:83; Aucamp, 1981:23; Ridderbos 1966:479 e.v.). 
Daar is ' $n$ harmonie tussen charisma en amp - 'n vervlegtheid en noue verband tussen charisma en amp, volgens Ridderbos. Dit het duidelik geword dat die verhouding nie antiteties gesien kan word nie, ook nie asof die een uit die ander ontwikkel het nie (soos Michel meen), of dat die gawes van die een déúr hom na die ander oorgedra kan word nie (soos Lauterburg voorstel).

\section{Perspektief op die begrip charisma}

In die Nuwe Testament blyk dit duidelik dat Christus sy kerk volgens 'n bepaalde wyse wil laat versorg en regeer. Ons moet die kerk altyd in sy trinitariese fundering en bestaanswyse verstaan, waarby die Vader, Seun en Heilige Gees elkeen besonderlik en ook as één God werksaam en betrokke is en bly (vgl. Venter, 1988:95-98).

Die kerk is die Godsvolk, die tempel van die Heilige Gees en die liggaam van Christus; dit is die volk van die nuwe verbond in die bedeling van die Heilige Gees. As sodanig staan die kerk dus in 'n besonder noue verhouding tot die koninkryk van God wat kom. Vir die lewe van die kerk het die Vader sy Seun gestuur en vanuit die Vader en die Seun is die Gees met Pinkster uitgestort.

Jesus Christus openbaar Homself as die groot gewer, soos blyk uit die volgende: Matteus 28:18-20 (opdraggewer); Johannes 21:15-17 (opdrag tot herderlike versorging); 1 Korintiërs 12:28 (etheto); Romeine 12 (charismata); Efesiërs 4:8 (edoken domata); 1 Korintiërs 12:4-6 (charismata, diakonia, energemata) en in 1 Korintiërs 12:1 (pneumatika) (vgl. Du Plooy, 1979:40-45; Te Velde, 1992:74-122). Geestesgawes (pneumatika) en genadegawes (charismata) kan as sinonieme beskou word (Conzelmann, 1974: 403).

Skrifgegewens in byvoorbeeld Efesiërs 4:11 e.v. en 1 Korintiërs $12: 28$ is vir die doeleindes van die kerkregering belangrik, omdat dit duidelik word dat God die diakonia en die charismata "in die kerk" gestel het. Dit is 'n blywende reëling van God ter wille van die opbou van die kerk.

Die gegewens in 1 Korintiërs, Romeine en Efesiërs is verhelderend ten opsigte van die vraag na die bedoeling, betekenis en die samehang tussen die charismata en diakonia. Du Rand (1988:83 e.v.) het onder meer 'n eksegetiese studie daarvan gemaak.

Die begrip charisma is 'n tipiese Pauliniese term; 'n verbale selfstandige naamwoord wat op 'n genadegawe dui. Charisma is verwant aan charis, wat 'n Griekse weergawe van die Hebreeuse 
hen is en dui op God se guns en genade (Du Rand, 1988:78). In die algemeen het die woord charisma nie 'n godsdienstige betekenis gehad nie, maar bloot op 'n geskenk gedui.

Die woord charisma kom 17 keer voor in die Nuwe Testament en met uitsondering van 1 Petrus 4:10, kom dit net in die Pauliniese Briewe voor. Dit lyk asof Paulus hiermee die geestelike toerusting wat God gee en wat vir die dienswerk in die kerk nodig is, beskryf (Du Rand, 1988:78).

Vervolgens word kortliks die definitiewe betekenis van die charismata bespreek, terwyl ook gewys word op minstens drie wanopvattings:

Die eerste wanopvatting, volgens Küng (1967:210-212), is wanneer gedink word dat charismata slegs buitengewone verskynsels aandui. Paulus het die sogenaamde buitengewone charismata, soos glossolalie wat ook in die ekstatiese mistiek van die Hellenisme voorgekom het, aanvaar (Küng, 1967:210). Tog ag Paulus die profesie veel belangriker (1 Kor. 14) en stel die dienskarakter voorop. Volgens Küng is die egte charisma daar waar dit 'n dienskarakter vertoon en dit tot opbou en nut van die kerk aangewend word.

Die woord charisma het sowel ' $n$ algemene as 'n meer tegniese betekenis. Die algemene betekenis dui op die verlossingsdaad van Christus (Rom. 5:15 e.v.) of op die ewige lewe (Rom. 6:23). Die tegniese betekenis dui op die besondere funksies wat die individuele gelowige moet doen en in staat is om te verrig, juis as gevolg van die feit dat daar 'n gawe voor gegee is.

Ten opsigte van die tegniese betekenis, kan verder drie kategorieë charismata onderskei word (Küng 1967:213):

- Eerstens is die genadegawes van verkondiging - hiertoe behoort die funksies van die apostels, profete, leraars en evangeliste.

- Tweedens is die charismata van hulpverlening - hiertoe behoort die funksies van die diakens, bepaalde vroue en weduwees.

- Derdens is die charismata van leiding - hiertoe behoort die funksies van die ouderlinge, herders en voorgangers.

'n Tweede misvatting is om te dink dat die charismata dui op begaafdheid eerder as op die funksies van hulp, leiding en diens aan iemand anders (vgl. Te Velde, 1992:76-84). 
'n Derde fout is om charismata te wil beperk tot bepaalde persone of sekere enkelinge. In hierdie geval word nie raakgesien nie dat God aan elkeen gee soos dit Hom behaag (1 Kor. 12:7; 1 Pet. 4:10). Küng (1967:216) konkludeer dus tereg dat die charismatiese ordening elke eenmansisteem uitsluit.

Die Nuwe Testament toon die kriteria wat in ag geneem moet word wanneer genadegawes aangewend word:

- Die geestesgawes, net soos die genadegawes, kan nie buite die Woord van God aangewend word nie. Die kerk kan alleen opbouend besig wees wanneer dit geskied op die belydenisbasis dat Jesus die Christus is (Joh. 14:26; 15:26; 1 Kor. 12:3). Die Gees werk juis dáár waar die belydenis dat Jesus die Here en Koning is, kragtig na vore kom.

- Liefde as vrug van die Gees is die belangrikste motief wat iemand moet lei en inspireer wanneer die genadegawes beoefen word (1 Kor. 13; Aucamp, 1981:42).

- In 1 Korintiërs 12 is dit opvallend hoe die gawes van een lid tot die ander aangewend moet word. Dit wys op die diensmotief.

- Die kriterium van die opbou van die kerk is baie prominent. In 1 Korintiërs 14 kom dit telkens na vore.

- Genadegawes moet aangewend word met die oog op wat nuttig is (1 Kor. 12:7). Glossolalie word in vergelyking met ander gawes, soos profesie, nie waarlik nuttig aangewend nie (Floor, 1979:96).

- Aan die einde van die gedeelte in die eerste brief aan die Korintiërs (14:26-40) stel Paulus die belangrike kriterium van die orde en ordelikheid. Daar moenie onordelike en onbeheersde optredes in die kerk wees nie (Aucamp, 1981:46).

Samevattend kan gestel word dat die charismata dui op 'n taak en roeping van God wat tot elke individuele gelowige gerig word. Aan diesulkes bied dit die vermoë en toerusting om een of ander besondere diens of taak tot opbou van die kerk te verrig. In die diens word die charisma 'n vaste werksaamheid, 'n reëling in die kerk (Ridderbos, 1966:497-498).

\section{Perspektief op die amp}

Die begrip amp word hier hoofsaaklik in die algemeen behandel en dus val die fokus op die woord diakonia. 
Daar is ook ander woorde wat soms gebruik word en wat dui op een of ander diens of amp, naamlik oikonomia (bediening, huishouding), leitourgia (dienswerk) en latreia (godsdienstige diens). Te Velde (1992:101 e.v.) behandel die verskillende Nuwe-Testamentiese woorde en terme wat in verband met die dienste of ampte gebruik word. Die Here het op 'n rojale manier voorsien, sodat daar genoeg instrumente en funksies in sy kerk sal wees om sy kerk op te bou.

Küng (1967:445) wys daarop dat die hele Nuwe Testament opvallend die gewone woorde wat voorkom in die staatkundige en siviele lewe en vir amp gebruik word, soos arche, time en telos vermy, omdat dit deurgaans dui op heerskappy en mag. In plaas daarvan gebruik die Nuwe Testament die woord diakonia (diens). Daar is ook nog ander woorde soos exousia (gesag - Luk. 23:7), baros (mag, 1 Tes. 2:7) wat wel in die Nuwe Testament voorkom, maar wat nie direk vir die funksie van 'n dienaar van Christus gebruik word nie. Verder is die gebruik van doulos opvallend (Fil. $1: 1$; Tit. 1:1). Soos diakonos dui doulos daarop dat die karakter van die diens/amp is om nederige en toegewyde werk in belang van die eienaar en Here, Jesus Christus, te verrig.

Die woord diakonia het verskillende betekenisse in die Nuwe Testament (Beyer, 1968:87; Roberts, 1976:16-19). Dit beteken in besonder die vervulling van 'n plig of dienswerk in die kerk van Jesus Christus. Paulus noem sy werk/diens in Romeine 11:13 'n diakonia (vgl. ook 2 Kor. 3:3; Hand. 6:4; 2 Kor. 8:19, 20). Die diens wat verrig word, is ten diepste diens aan Christus (2 Kor. 11:23; Kol. $1: 7 ; 2$ Kor. $6: 4$ ) of diens aan die evangelie (Efes. 3:7).

Aan die begrip diens is ook die begrip roeping ten nouste gekoppel (Hand. 13:2; 20:28). Paulus praat in 1 Timoteus $3: 1$ van die begeerte tot die diens, bedoelende roeping. Küng (1967:451) sê van die diens (diakonia) dieselfde as wat hy van die charismata gesê het, naamlik dat dit as 'n roeping van God gesien moet word wat tot die individu gerig is, met die oog op 'n bepaalde taak of diens en wat 'n mens daartoe in staat stel.

Brockhaus (1972:24; vgl. ook Du Rand, 1988:79) onderskei die volgende komponente wat die amp in die Nuwe Testament onderskei:

- Die amp moet permanent wees.

- Dit moet deur die kerk aanvaar en erken word.

- Die amp moet gerespekteer word. 
- Die betrokkene moet op 'n ordelike manier in diens gestel word, bv. deur handoplegging.

- Aan die amp is daar ook 'n juridiese element verbonde.

\section{Verhouding tussen charisma en amp}

Die charisma en amp kan nooit antiteties gestel word nie. Dit is interafhanklik van mekaar en gerig op mekaar. Sonder die genadegawe kan geen diens gelewer word nie. 'n Vergelyking tussen Paulus se briewe aan die Korintiërs en Romeine aan die een kant, met die Pastorale Briewe aan die ander kant, lewer bewys daarvan dat dit wat dikwels in eersgenoemde briewe as genadegawes beskryf is, volgens die Pastorale Briewe in die bepaalde diens van herder, ouderlinge of diaken 'n vaste werksaamheid word (Ridderbos, 1967:495). Die diakonia is volgens Ridderbos die kensketsing van die wyse waarvolgens die charismata in die kerk funksioneer.

Smith kom in sy reaksie teen diegene wat van 'n "Tweede Reformasie" praat, tot die konklusie dat geen teenstelling tussen 'n sogenaamde charismatiese kerk en 'n amptelike kerk moontlik is nie. Hy toon ook aan dat daar verskillende voorbeelde is wat aandui hoe charismata "find their counterparts in the qualifications laid down for elders/bishops and deacons in the Pastoral epistles (compare Rom. 12:7-8 with 1 Tim. 3:2, 10; Tit.1:9)" (Smith, 1999:151 e.v.)

Dit is duidelik dat daar geen konflik tussen Paulus se briewe is nie, maar daar is duidelik ook ' $n$ ontwikkelingsgang, namate Paulus besef dat sy diens tot 'n einde kom. In Paulus se brief aan Timoteus (veral 1 Tim. 3:15) word die doel van sy skrywe duidelik: Hy wil naamlik bepaalde opdragte gee oor die gedrag van die kerk nou dat hy by die oordrag van die amp na Timoteus gekom het. Daarom (vgl. Ridderbos, 1967:100) word daar duideliker voorskrifte gegee oor die ampte, maar dit moet egter saamgelees word met wat hy vroeër oor die genadegawes gesê het.

\section{Die betekenis vir die kerkregering}

Wanneer Paulus in Efesiërs 4 (4:8; 11-16) skryf oor die dienste wat Christus as verhoogde Here in en aan die kerk gegee het, is dit meteens duidelik hoe belangrik die charisma en amp vir die opbou van die kerk van Christus is. 
Dit is duidelik dat die Here Christus as die enigste Hoof van die Kerk weereens alles gegee het wat ons in hierdie sondige en onvolmaakte wêreld vir die toerusting en opbou van die kerk nodig het. Daar is 'n orde van funksionaliteit gestel (Roberts, 1971:29; Du Rand, 1988:90). Die dienste wat gegee is, vind hulle eenheid daarin dat hulle Christus aan die kerk bedien, sodat die kerk uit Hom en tot Hom mag opgroei. In hierdie proses moet aan al die gestelde kriteria voldoen word.

Diegene wat in die diens van toerusting en opbou van die kerk geroep is en wat daarvoor die genadegawes ontvang het, hoef slegs maar profeties, priesterlik en koninklik die Woord van God te bedien, want die Woord rus volkome toe (2 Tim. 3:16-17).

Vir die kerkregering is dit wesenlik belangrik dat erken en bely moet word dat Christus as verhoogde Here, vanuit die hemel sy Gees en al die gawes, kragte en dienste gegee het waarmee sy geroepe dienaars in staat gestel word om die heiliges vir hulle dienswerk toe te rus (vgl. Venter, 1988:95-98).

Só gesien, is die doel van die kerkregering toerusting van die gelowiges - dit is om toe te sien dat elkeen gelei en bedien word sodat hy of sy kan doen wat van so 'n persoon verwag kan word. Volgens Efesiërs 4:7-16 is die dienste (bv. die herders en die leraars) geroep om soos organe of ligamente (hafai) in 'n liggaam, die hele liggaam goed te laat funksioneer vanuit Christus as die Hoof (orgaan) (vgl. Versteeg, 1988:49-74).

Die doel van die genadegawes en die dienste trek saam in die feit dat die kerk van Christus opgebou moet word. Dit sluit die bybou van nuwe gelowiges en die groei van die kerk in geloof, hoop en liefde in.

Hoewel daar 'n verskeidenheid genadegawes en dienste is, is die taak en roeping van almal gerig op die één koninkryk van God, die één kerk van Christus (die één liggaam) en moet die eenheid van die kerk daardeur gedien word (Efes. 4:12-13). Die kerk is wêreldwyd 'n geloofsunie en daartoe moet die funksionering van die dienste, as gawes van God aan die kerk, bydra (Du Plooy, 1979:66).

Die dienste en gawes wat God in en aan sy kerk gee, werk primêr plaaslik - dit wil sê daar waar die kerk van Jesus Christus bestaan en funksioneer. Die dienste en gawes wat God aan sy gelowiges in die kerk gee, moet ook ter wille van en tot opbou van die kerk in die algemeen aangewend word. Die opbou kan veral geskied wanneer die kerke in meerdere vergaderings of sinodes byeen kom. ' $n$ 
Meerdere vergadering is eerstens ' $n$ vergadering van meer kerke (plaaslike gemeentes) en dus tegelyk ook 'n geleentheid waar meer gawes teenwoordig is. In so 'n samekoms van meer gawes kan vrugbaar saam gesoek en gevra word na die wil van God vir sy kerk en na die regering van Jesus Christus as die enigste Hoof van die kerk. God het per slot van rekening sy Gees en met Hom die gawes (charismata) en dienste inderdaad in die kerk as sy liggaam gegee. Hierdie liggaam moet as sy één, heilige, algemene (katolieke en ekumeniese) en apostoliese kerk op aarde opgebou word! Hiertoe is sinodes van kerke in die verskillende lande diensbaar, maar ook die ekumeniese liggame (rade en konferensies) moet daaraan diensbaar wees. Juis oor die grense van volk, land en taal heen moet kerke van mekaar se dienste en gawes gebruik kan maak. Ons is immers geroep om saam met al die gelowiges te probeer begryp hoe geweldig groot die liefde van God in Christus is (Ef. 3:18; 1 Kor. 1:2).

\section{Slotopmerkings}

Die Nuwe-Testamentiese gegewens oor die charismata en diakonia behoort opnuut deur die teologiese dissiplines, soos Praktiese Teologie en Kerkreg, in besonder in die fokus te kom in belang van die opbou en versorging van die kerk van Christus.

Die kerk is en moet charismaties wees, maar op so 'n wyse dat die genadegawes wat aan elkeen gegee is, in die ordelike dienswerk van hulle wat daarvoor deur God self geroep is, tot opbou aangewend word.

\section{Geraadpleegde bronne}

AUCAMP, M. 1981. Charisma en amp in die bevestigingsformuliere: 'n Kerkregtelike studie. Potchefstroom: PU vir CHO. (Th.M.-verhandeling.)

BEYER, H.W. 1968. Diakonia, diakonos. (In Kittel, G., red. Theological dictionary of the New Testament. Vol II. Grand Rapids: Eerdmans. p.8793.)

BROCKHAUS, 1972. Charisma und Amt: die Paulinische Charismenlehre auf dem Hintergrund der frühchristlichen Gemeindefunktionen. Wuppertal: Brockhaus.

BURGER, I. 2004. Kerkleiers trek op groot skaal saam: In meer as een opsig lê 'n nuwe seisoen voor. Beeld: 10, Aug. 2.

CONZELMANN, H.G. 1974. Charisma. (In Friedrich, G., red. Theological dictionary of the New Testament. Vol IX:402-406. Grand Rapids: Eerdmans. p. 4.)

DU PLOOY, A. le R. 1979. Ekklésia en meerdere vergaderinge. Potchefsroom: $\mathrm{PU}$ vir $\mathrm{CHO}$. (Th.M.-verhandeling.) 
DU RAND, J.A. 1988. Charisma en amp - 'n Pauliniese eksegetiese verkenning. (In Rossouw, P.J., red. Gereformeerde ampsbediening. Pretoria: NG Kerkboekhandel. p. 75-94.)

FLOOR, L. 1979. Hy wat met die Heilige Gees doop. Pretoria: NG Kerkboekhandel.

FUNG, R.Y.K. 1980. Charismatic versus organized ministry: An examination of an alleged antithesis. Evangelical Quarterly, 52(O-D):195-214.

HARNACK, A. 1910. Enstehung und Entwickelung der Kirchenverfassung und des Kirchenrechts in den zwei ersten Jahrhunderten. Leipzig: Hinrich.

HOLL, K. 1928. Der Kirchenbegriff des Paulus in seinem Verhältnis zu dem Urgemeinde. Tübigen: Mohr.

KÜNG, H. 1967. De Kerk. (Uit Duits vertaal deur Hans Wagemans.) Antwerpen: Paul Brand Hilversum.

LEKKERKERKER, A.F.N. 1971. Oorsprong en funktie van het ambt. 's-Gravenhage: Boekencentrum.

RIDDERBOS, H. 1966. Paulus, ontwerp van zijn theologie. Kampen: Kok.

RIDDERBOS, H. 1967. De Pastorale Brieven. (In Commentaar op het Nieuwe Testament. Kampen: Kok.)

ROBERTS, J.H. 1971. Die Gees en die charismata in die briewe van Paulus. (In Nuwe-Testamentiese Werkgemeenskap van Suid-Afrika. Die pneuma by Paulus: enkele gedagtes oor die Heilige Gees in die briewe van Paulus (with summaries in English). Potchefstroom: Pro Rege. p. 21-36.) (Neotestamentica, 3.)

ROBERTS, J.H. 1976. Can church offices be found in Paul? (In NuweTestamentiese Werkgemeenskap van Suid-Afrika. Ministry in die Pauline Letters. Pretoria: Nuwe-Testamentiese Werkgemeenskap van Suid-Afrika. p. 1-19.) (Neotestamentica, 10.)

SMITH, R.S. 1999. A "Second Reformation"! "Office" and "Charisma" in the New Testament. Reformed Theological Review, 58(3):151-162, December.

SOHM, R. 1892. Kirchenrecht. I. Band. München: Dunker \& Humblot.

TE VELDE, M. 1992. Gemeente opbouw 2. Bijbelse basisprincipes voor het functioneren van de christelijke gemeente. Barneveld: De Vuurbaak.

VENTER, C.J.H. 1988. Amp en ampsdraer - gesigspunte uit die Nuwe Testament. (In Rossouw, P.J., red. Gereformeerde Ampsbediening. Pretoria: NG Kerkboekhandel. p. 95-108.)

VERSTEEG, J.P. 1988. Het karakter van het ambt volgens Efeziërs 4:7-16. (In Rossouw, P.J., red. Gereformeerde Ampsbediening. Pretoria: NG Kerkboekhandel. p. 75-94.)

\section{Kernbegrippe:}

amp; dienste in die kerk

charisma; genadegawes, geestelike gawes

diens; amp, funksie

genadegawes; gawes, geestesgawes

kerkregering; kerkorde, kerkreg 
Key concepts:

charisma; gifts, spiritual gifts

church polity; church order, government of the church

gifts; charismata

office; function, task

service; office, function 
